\title{
Urinary continence following laparoscopic radical prostatectomy: Association with postoperative membranous urethral length measured using real-time intraoperative transrectal ultrasonography
}

\author{
YOICHI MIZUTANI, HIROSHI UEHARA, YUTAKA FUJISUE, SHIZUKO TAKAGI, TAKESHI NISHIDA, \\ TERUO INAMOTO, TAKANOBU UBAI, HAYAHITO NOMI, YOJI KATSUOKA and HARUHITO AZUMA
}

Department of Urology, Faculty of Medicine, Osaka Medical College, Osaka 569-8686, Japan

Received June 23, 2011; Accepted September 30, 2011

DOI: $10.3892 / \mathrm{ol} .2011 .446$

\begin{abstract}
Urinary incontinence is a major complication following radical prostatectomy. The aim of the present study was to assess the association between urinary continence following laparoscopic radical prostatectomy (LRP) and various factors measured using real-time intraoperative transrectal ultrasonography (TRUS). Patients $(n=53)$ with localized prostate cancer underwent LRP in combination with real-time intraoperative TRUS navigation and were evaluated for urinary continence for more than 6 months following LRP. Prostate size, membranous urethral length (MUL) and bladder-urethra angle were measured using real-time intraoperative TRUS immediately before and after surgery. Urinary continence was regained by 4,15 and 27 patients 1,3 and 6 months after LRP, respectively. Longer postoperative MUL was significantly correlated with recovery of urinary continence 1, 3 and 6 months after LRP. In addition, an increase in difference between preoperative and postoperative MUL was also associated with superior continence. No correlation was observed between postoperative MUL and the rate of tumor-positive surgical margins. Larger prostate volume was correlated to postoperative continence 6 months after surgery. Shorter operation time and less blood loss resulted in postoperative urinary continence 1 month after LRP. Preoperative MUL, bladder-urethra angle, age and body mass index had no
\end{abstract}

Correspondence to: Dr Yoichi Mizutani, Department of Urology, Faculty of Medicine, Osaka Medical College, 2-7 Daigakumachi, Takatsuki, Osaka 569-8686, Japan

E-mail: uro046@poh.osaka-med.ac.jp

Abbreviations: BMI, body mass index; LRP, laparoscopic radical prostatectomy; MUL, membranous urethral length; RP, radical prostatectomy; $\mathrm{SD}$, standard deviation; TRUS, transrectal ultrasonography

Key words: urinary continence, membranous urethral length, laparoscopic radical prostatectomy, transrectal ultrasonography correlation with urinary continence. Postoperative MUL was the most significant factor for early recovery of urinary continence following LRP. These results indicate that preservation of longer urethra during surgery may be recommended without tumor-positive surgical margins.

\section{Introduction}

Radical prostatectomy (RP) is one of the definitive therapy options for localized prostate cancer. However, one of the major adverse events that impair quality of life is urinary incontinence. It has been reported that the rates of urinary incontinence following RP range from 6 to $69 \%(1,2)$. This range is wide due to variations in the definition of urinary incontinence, patient selection and surgical technique. A number of risk factors for urinary incontinence have been analyzed $(3,4)$. These include preoperative factors (patient age, body weight and prostate volume) and intraoperative factors (operative method: open vs. laparoscopy, bladder-neck preservation, urethral length preservation, neurovascular bundle sparing and puboprostatic ligament sparing). Although these factors have been examined, few achieved independent significance (i.e., high-level evidence) with regard to urinary continence. Moreover, several reported results have been controversial irrespective of their studying the same factors. Therefore, the identification of predictive markers for urinary continence following RP, which are easily measured, is essential.

Laparoscopic radical prostatectomy (LRP) is less invasive compared with open procedures and is therefore performed in our institution. In addition, the real-time intraoperative transrectal ultrasonography (TRUS) navigation system is combined with LRP to prevent surgical complications such as rectal injury and to identify anatomy such as bladder-prostate and prostate-urethra borders and neurovascular bundle for accurate dissection. To the best of our knowledge, no studies on various intraoperative anatomical evaluation of membranous urethral length (MUL), bladder-urethra angle and prostate size have been performed thus far in LRP using TRUS. The present study evaluated the relationship between urinary continence following LRP and various factors measured using real-time intraoperative TRUS. 


\section{Materials and methods}

Patients. The current study was conducted at the Department of Urology, Faculty of Medicine, Osaka Medical College, Japan, between 2009 and 2010. The objectives and contents of this study and the significance of participation were explained to the patients. Their informed consent was obtained before the study commenced. This study was performed with the approval of the local Human Investigations Committee.

A total of 53 patients with localized prostate cancer underwent LRP in combination with the real-time intraoperative TRUS navigation system and were evaluated for urinary continence for $>6$ months after LRP. The age range of the patients was 60-78 years (median 71 years). Histological diagnosis revealed that the patients exhibited adenocarcinoma. Their pathological staging according to TNM classification was: T2 $(n=48)$, and T3 $(n=5)$, respectively. The Gleason score sum was: $<7(\mathrm{n}=11), 7(\mathrm{n}=27)$, and $>7(\mathrm{n}=15)$, respectively.

$L R P$ procedure with real-time intraoperative TRUS navigation. Antegrade LRP was performed retroperitoneally. Preservation of membranous urethra, puboprostatic ligament sparing and bladder-neck sling suspension were performed for early recovery of urinary continence.

LRP was accompanied with real-time intraoperative TRUS guidance for the prevention of rectal injury, anatomical detection for accurate dissection of bladder-prostate border and prostate-urethra border and preservation of neurovascular bundle. The Aloka Prosound $\alpha 6$ ultrasound system with a 5.5-7.5 MHz bi-plane probe was used for TRUS navigation. TRUS was performed by an experienced urologist. MUL and bladder-urethra angle were measured immediately before and after LRP. Prostate size was also evaluated preoperatively. Pre- and postoperative MUL were defined as the distance from prostate apex to urethral bulb and the distance from bladder neck to urethral bulb, respectively. Bladder-urethra angle was defined as the angle between the anterior wall of the bladder and the membranous urethra.

Statistical analysis. Patients with urinary continence were defined as those using 0-1 pad per day. For statistical analysis, the Student's t-test was used. $\mathrm{P}<0.05$ was considered significant.

\section{Results}

Association between preoperative factors and urinary continence following LRP. Patients $(\mathrm{n}=53)$ with prostate cancer were evaluated for urinary continence for $>6$ months after LRP. Urinary continence was regained by $4(7.5 \%)$, $15(28.3 \%)$ and $27(50.9 \%)$ patients 1,3 and 6 months after LRP, respectively.

The correlation between preoperative factors and urinary continence following LRP was examined. Preoperative factors included patient age, body mass index (BMI) and prostate volume measured by intraoperative TRUS. Patients with urinary continence 6 months after LRP exhibited larger prostate size, although no significant association was observed 1 and 3 months after surgery (Table I). There was no relationship between postoperative urinary continence and age or BMI (Table I).
Table I. Relationship between preoperative factors and urinary continence after LRP.

\begin{tabular}{lcccc}
\hline & & \multicolumn{4}{c}{ Postoperative period } \\
\cline { 3 - 5 } $\begin{array}{l}\text { Preoperative } \\
\text { factors }\end{array}$ & $\begin{array}{c}\text { Urinary } \\
\text { continence }\end{array}$ & $1 \mathrm{M}$ & $3 \mathrm{M}$ & $6 \mathrm{M}$ \\
& & & & \\
\hline Patient age & + & $73.0 \pm 3.0$ & $72.0 \pm 3.0$ & $71.0 \pm 4.0$ \\
$(71 \pm 4$ years $)$ & - & $70.0 \pm 5.0$ & $70.0 \pm 5.0$ & $70.0 \pm 5.0$ \\
BMI & + & $22.7 \pm 1.8$ & $24.1 \pm 1.8$ & $23.4 \pm 1.9$ \\
$(23.4 \pm 2.1)$ & - & $23.5 \pm 2.1$ & $23.2 \pm 2.2$ & $23.4 \pm 2.3$ \\
Prostate size & + & $17.2 \pm 6.1$ & $24.0 \pm 10.3$ & $23.5 \pm 10.7^{\text {a }}$ \\
$\left(20.8 \pm 9.3 \mathrm{~cm}^{3}\right)$ & - & $21.1 \pm 9.5$ & $19.6 \pm 8.7$ & $18.0 \pm 6.7$ \\
\hline
\end{tabular}

${ }^{\mathrm{a}} \mathrm{p}<0.05$ vs. urinary continence (-).

Table II. Relationship between perioperative factors and urinary continence after LRP.

\begin{tabular}{|c|c|c|c|c|}
\hline \multirow{2}{*}{$\begin{array}{l}\text { Perioperative } \\
\text { factors } \\
(\text { mean } \pm \mathrm{SD})\end{array}$} & \multirow{2}{*}{$\begin{array}{c}\text { Urinary } \\
\text { continence }\end{array}$} & \multicolumn{3}{|c|}{ Postoperative period } \\
\hline & & $1 \mathrm{M}$ & $3 \mathrm{M}$ & $6 \mathrm{M}$ \\
\hline Oper: & + & $193 \pm 9^{\mathrm{a}}$ & 216 & $222 \pm 48$ \\
\hline$(224 \pm 47 \mathrm{~min})$ & - & $226 \pm 48$ & $227 \pm 46$ & $226 \pm 46$ \\
\hline Bloo & + & $393 \pm 239^{a}$ & $602 \pm 561$ & $651 \pm 532$ \\
\hline$(663 \pm 521 \mathrm{ml})$ & - & $685 \pm 533$ & $687 \pm 511$ & $676 \pm 520$ \\
\hline
\end{tabular}

${ }^{\mathrm{a}} \mathrm{p}<0.05$ vs. urinary continence (-).

Association between perioperative factors and urinary continence after LRP. Perioperative factors were operation time and blood loss. The mean time of operation was $224 \mathrm{~min}$ (SD: $47 \mathrm{~min}$ ). A correlation was found between short operation time and urinary continence 1 month after LRP; however, no significant association was observed 3 and 6 months after surgery (Table II). The mean intraoperative blood loss was $663 \mathrm{ml}$ (SD: $521 \mathrm{ml}$ ). Urinary continence 1 month after LRP was associated with low blood loss; however, no statistical significance was observed 3 and 6 months after LRP (Table II).

Relationship between intraoperative factors measured using real-time TRUS and urinary continence following $L R P$. Intraoperative factors measured by TRUS were MUL and bladder-urethra angle. MUL and bladder-urethra angle were evaluated immediately prior and subsequent to LRP. Preservation of membranous urethra, puboprostatic ligament sparing and bladder-neck sling suspension were performed for early recovery of urinary continence.

The mean pre- and postoperative MUL were 1.0 and $2.2 \mathrm{~cm}$ (SD: 0.2 and $0.3 \mathrm{~cm}$ ), respectively. The mean difference between pre- and postoperative MUL was $1.2 \mathrm{~cm}$ (SD: $0.3 \mathrm{~cm}$ ). Urinary continence following LRP was correlated with longer MUL (Table III). Increased difference between pre- and post- 
Table III. Relationship between intraoperative factors measured by real-time TRUS and urinary continence after LRP.

\begin{tabular}{|c|c|c|c|c|}
\hline \multirow{2}{*}{$\begin{array}{l}\text { Intraoperative } \\
\text { factors } \\
(\text { mean } \pm \mathrm{SD})\end{array}$} & \multirow{2}{*}{$\begin{array}{l}\text { Urinary } \\
\text { continence }\end{array}$} & \multicolumn{3}{|c|}{ Postoperative period } \\
\hline & & $1 \mathrm{M}$ & $3 \mathrm{M}$ & $6 \mathrm{M}$ \\
\hline Preoperative MUL & + & $1.2 \pm 0.2$ & $1.1 \pm 0.2$ & $1.0 \pm 0.2$ \\
\hline$(1.0 \pm 0.2 \mathrm{~cm})$ & - & $1.0 \pm 0.2$ & $1.0 \pm 0.2$ & $1.1 \pm 0.2$ \\
\hline Postoperative MUL & + & $2.6 \pm 0.1^{\mathrm{a}}$ & $2.4 \pm 0.3^{\mathrm{a}}$ & $2.3 \pm 0.2^{\mathrm{a}}$ \\
\hline$(2.2 \pm 0.3 \mathrm{~cm})$ & - & $2.1 \pm 0.3$ & $2.1 \pm 0.3$ & $2.0 \pm 0.3$ \\
\hline \multicolumn{5}{|l|}{$\begin{array}{l}\text { Difference between } \\
\text { pre/postoperative }\end{array}$} \\
\hline MUL & + & $1.5 \pm 0.2^{\mathrm{a}}$ & $1.3 \pm 0.2^{\mathrm{a}}$ & $1.3 \pm 0.2^{\mathrm{a}}$ \\
\hline$(1.2 \pm 0.3 \mathrm{~cm})$ & - & $1.1 \pm 0.3$ & $1.1 \pm 0.3$ & $1.0 \pm 0.3$ \\
\hline \multicolumn{5}{|l|}{$\begin{array}{l}\text { Preoperative } \\
\text { bladder-urethra }\end{array}$} \\
\hline angle & + & $125 \pm 13$ & $133 \pm 12$ & $134 \pm 13$ \\
\hline$\left(133 \pm 14^{\circ}\right)$ & - & $134 \pm 14$ & $133 \pm 14$ & $132 \pm 14$ \\
\hline \multicolumn{5}{|l|}{$\begin{array}{l}\text { Postoperative } \\
\text { bladder-urethra }\end{array}$} \\
\hline angle & + & $105 \pm 13$ & $111 \pm 14$ & $110 \pm 16$ \\
\hline$\left(107 \pm 17^{\circ}\right)$ & - & $107 \pm 17$ & $105 \pm 18$ & $104 \pm 18$ \\
\hline \multicolumn{5}{|l|}{$\begin{array}{l}\text { Difference between } \\
\text { pre/postoperative } \\
\text { bladder-urethra }\end{array}$} \\
\hline angle & + & $20 \pm 8$ & $22 \pm 9$ & $24 \pm 11$ \\
\hline$\left(26 \pm 15^{\circ}\right)$ & - & $27 \pm 16$ & $28 \pm 17$ & $29 \pm 18$ \\
\hline
\end{tabular}

${ }^{\mathrm{a}} \mathrm{p}<0.05$ vs. urinary continence (-).

operative MUL was also associated with urinary continence. However, there was no association between urinary continence and preoperative MUL.

The mean bladder-urethra angles prior and subsequent to $\mathrm{LRP}$ were $133^{\circ}$ and $107^{\circ}$ (SD: $14^{\circ}$ and $17^{\circ}$ ), respectively. Urinary continence after LRP was not associated with pre-/ postoperative bladder-urethra angle and the difference between pre- and postoperative bladder-urethra angle (Table III).

Pathological findings of surgical margin. We then examined the relationship between postoperative MUL and the rate of tumor-positive surgical margins. There was no correlation between postoperative MUL and the frequency of pathological surgical margins (Table IV).

\section{Discussion}

A number of studies have discussed a variety of risk factors that influence urinary incontinence following RP. Identification of the reliable risk factors may aid in the prevention of postoperative urinary incontinence and selection of patients. However, substantial controversy exists regarding the risk factors. The findings regarding the real-time intraoperative TRUS navigation system in combination with LRP in the present study have demonstrated for the first time that longer postoperative MUL was markedly associated with early recovery of urinary conti-
Table IV. Relationship between postoperative MUL and tumor-positive surgical margin rate.

\begin{tabular}{lc}
$\begin{array}{l}\text { Postoperative } \\
\text { MUL }\end{array}$ & $\begin{array}{c}\text { Tumor-positive surgical } \\
\text { margin rate }\end{array}$ \\
\hline $\begin{array}{l}\geq 2.2 \mathrm{~cm} \\
(\mathrm{n}=26)\end{array}$ & $11.5 \%$ \\
$\begin{array}{l}<.2 \mathrm{~cm} \\
(\mathrm{n}=27)\end{array}$ & $7.4 \%$ \\
\hline
\end{tabular}

nence after LRP. Additionally, longer MUL was not correlated with an increase in the tumor-positive resection margin rate. Although the data reported herein correspond to a small number of patients during a short-term follow-up, these results indicate that preservation of longer MUL during LRP may be significant in preventing postoperative urinary incontinence.

Several studies emphasized the significance of maximizing urethral length for favorable urinary control after RP. Myers recommended various operative methods for maintaining the length of urethral stump to achieve urinary continence after RP (5). Van Randenborgh et al maintained long urethral stump by intraprostatic dissection for a more rapid recovery of urinary continence following RP (6). A significant difference was observed in functional urethral length between urinary continent and incontinent patients who underwent RP $(7,8)$. We also demonstrated that long postoperative MUL was associated with early recovery of urinary continence following LRP. However, maximizing MUL at the risk of compromising tumor-positive surgical margins should be discouraged. In this study, there was no correlation between the length of postoperative MUL and the rate of tumor-positive surgical margins. These findings indicate that preservation of longer MUL without tumor-positive surgical margins may be crucial for the early recovery of postoperative urinary continence.

Certain authors measured MUL using urodynamic assessment (5,7-10). In other studies, MUL was examined using endorectal magnetic resonance imaging $(11,12)$. However, to the best of our knowledge, no studies are currently available regarding the measurement of pre- and postoperative MUL by real-time intraoperative TRUS navigation system combined with LRP. Real-time intaroperative TRUS navigation system is easily utilized. In addition, real-time intraoperative TRUS guidance with the doppler system is advantageous for the identification of accurate bladder-prostate and prostate-urethra borders for dissection, prevention of rectal injury and preservation of neurovascular bundle. These findings indicate that the combination of LRP and real-time TRUS may be recommended.

Puboprostatic ligament sparing and bladder-neck sling suspension were performed for early recovery of urinary continence following LRP (13). Poore et al demonstrated an earlier return to urinary continence for patients who underwent puboprostatic ligament sparing (14). In contrast, Deliveliotis et al revealed that puboprostatic ligament sparing was not essential for rapid return to urinary continence after RP (15). In the present study, puboprostatic ligament sparing and bladder-neck sling suspension was evaluated by 
bladder-urethra angle measured using real-time intraoperative TRUS. Urinary continence following LRP was not associated with pre/postoperative bladder-urethra angle and the difference between pre- and postoperative bladder-urethra angle. These findings indicate that puboprostatic ligament sparing and bladder-neck sling suspension may not be significant for the early recovery of continence after LRP.

A review of CaPSURE data revealed that patients with large prostate volume exhibited a lower urinary continence rate (16). Conversely, the present study demonstrated that large prostate size was associated with postoperative urinary continence 6 months after LRP. However, no significant association was observed 1 and 3 months after LRP. Another study found that no correlation was observed between prostate volume and urinary continence following RP (17). Since the mechanisms responsible for the discrepancy are unclear, further investigations are required.

Eastham et al found that there was an association between intraoperative blood loss and urinary incontinence following RP (17). However, Lepor et al demonstrated that there was no relationship between blood loss and continence following RP (18). This study revealed that reduced blood loss resulted in urinary continence 1 month after LRP; however, no significant association was observed 3 and 6 months after surgery. Blood loss is thought to be associated with other technical factors. These findings indicate that blood loss may not be a significant predictive indicator for urinary continence following LRP.

A number of studies have shown that there was a correlation between patient age and postoperative urinary continence following RP $(1,8,17,19,20)$. Eastham et al reported 615 radical prostatectomies performed by a single surgeon (17). Catalona et al reviewed a large series (20). However, findings of other studies showed that age was not a risk factor for urinary incontinence following RP $(18,21)$. Our data confirmed the latter results. The discrepancy may be due to patient selection and methodology.

Patient weight and BMI were reported to be predictive markers for urinary incontinence following RP $(16,17)$. However, the present study revealed that there was no correlation between BMI and urinary continence following LRP. One of the reasons responsible for the discrepancy may be technical factors affected by BMI.

In conclusion, the preservation of long MUL and a low tumor-positive surgical margin rate appears to be feasible in prostate cancer patients undergoing LRP and offers a more favorable quality of life by reducing postoperative urinary incontinence.

\section{References}

1. Wei JT, Dunn RL and Marcovich R: Prospective assessment of patient reported urinary continence after radical prostatectomy. J Urol 164: 744-750, 2000.
2. Steiner MS, Morton RA and Walsh PC: Impact of anatomical radical prostatectomy on urinary continence. J Urol 145: 512-514, 1991.

3. Cambio AJ and Evans CP: Minimising postoperative incontinence following radical prostatectomy: considerations and evidence. Eur Urol 50: 903-913, 2006.

4. Loughlin KR and Prasad MM: Post-prostatectomy urinary incontinence: A confluence of 3 factors. J Urol 183: 871-877, 2010.

5. Myers RP: Male urethral sphincteric anatomy and radical prostatectomy. Urol Clin North Am 18: 211-231, 1991.

6. Van Randenborgh H, Paul R, Kubler H, Breul J and Hartung R: Improved urinary continence after radical retropubic prostatectomy with preparation of a long partially intraprostatic portion of the membranous urethra: an analysis of 1013 consecutive cases. Prostate Cancer Prostatic Dis 7: 253-257, 2004.

7. Presti JC Jr, Schmidt RA and Narayan PA: Pathophysiology of urinary incontinence after radical prostatectomy. J Urol 143: 2201-2206, 1990

8. Hammerer P and Huland H: Urodynamic evaluation of changes in urinary control after radical retropubic prostatectomy. J Urol 157: 233-239, 1997.

9. Kielb SJ and Clemens JQ: Comprehensive urodynamics evaluation of 146 men with incontinence after radical prostatectomy. Urology 66: 392-396, 2005.

10. Constantinou CE and Freiha FS: Impact of radical prostatectomy on the characteristics of bladder and urethra. J Urol 148: 1215-1219, 1992.

11. Paparel P, Akin O, Sandhu JS, Otero JR, Serio AM, Scardino PT, Hricak $\mathrm{H}$ and Guillonneau B: Recovery of urinary continence after radical prostatectomy: association with urethral length and urethral fibrosis measured by preoperative and postoperative magnetic resonance imaging. Eur Urol 55: 629-639, 2009.

12. Coakley FV, Eberhardt S, Kattan MW, Wei DC, Scardino PT and Hricak $\mathrm{H}$ : Urinary continence after radical retropubic prostatectomy: Relationship with membranous urethral length on preoperative endorectal magnetic resonance imaging. J Urol 168: 1632-1635, 2002.

13. Steiner MS: The puboprostatic ligament and the male urethral suspensory mechanism: an anatomic study. Urology 44: 530-535, 1994.

14. Poore RE, McCullough DL and Jarow JP: Puboprostatic ligament sparing improves urinary continence after radical retropubic prostatectomy. Urology 51: 67-72, 1988.

15. Deliveliotis C, Protogerou V and Alargof E: Radical prostatectomy: bladder neck preservation and puboprostatic ligament sparing-effects on continence and positive margin. Urology 60: 855-890, 2002

16. Konety BR, Sadetsky N and Carroll PR: Recovery of urinary continence following radical prostatectomy: the impact of prostate volume-analysis of data from CaPSURE database. J Urol 177: 1423-1428, 2007.

17. Eastham JA, Kattan MW and Rogers E: Risk factors for urinary incontinence after radical prostatectomy. J Urol 156: 1707-1714, 1996.

18. Lepor $\mathrm{H}$ and Kaci L: The impact of open radical prostatectomy on continence and lower urinary tract symptoms: a prospective assessment using validated self-administrated outcome instruments. J Urol 171: 1216-1220, 2004.

19. Kerr LA and Zincke H: Radical retropubic prostatectomy for prostate cancer and the elderly and the young: complications and prognosis. Eur Urol 25: 305-310, 1994.

20. Catalona WJ, Carvalhal GF and Mager DE: Potency, continence and complication rates in 1,870 consecutive radical retropubic prostatectomies. J Urol 162: 433-439, 1999.

21. Goluboff ET, Saidi JA and Mazer S: Urinary continence after radical prostatectomy: the Columbia experience. J Urol 159: 1276-1281, 1998. 